\title{
Population and Oral Hygiene (World Population Day Editorial Comment)
}

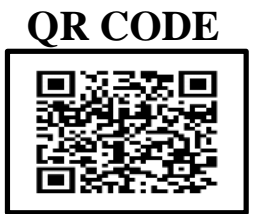

World Population Day is an annual observance which occurs on the $11^{\text {th }}$ July which is when the issues pertaining to health are discussed and reported for the world at glance, every sector of health and various distributaries take note of the diseases, prevention and treatment for the incidence rate of bacterial or fungal growth and the dwelling of the infection spread and control measure which need to be opted.

The mouth and oral cavity are focal points for interaction of the body with external environment, speech, chewing, swallowing, and the early stages of digestion are all vital physiological functions that involve the oral cavity and the mouth plays a role in psychological identity.

Oral cavity is by far the most neglected area of the human body the reason of neglect being the non coverage under insurance schemes or the hospital set up and private finance company, however with the corporate multi-national firms having a reimbursement on the procurement of the bill is available. Government includes the CGHS policies for the medical facilities wherein the dental amenities are healed and sealed.

Oral hygiene and its importance with maintenance measures evolves the general health parameters and optimizes the ill- effects on the systemic diseases, giving rise to the positive feedback mechanism seen in the oral microbial flora.

Approximately 700 species of prokaryotes have been identified in it. These species belong to 185 genera and 12 phyla, of which approximately $54 \%$ are officially named, $14 \%$ are unnamed (but cultivated) and $32 \%$ are known only as uncultivated phylotypes. ${ }^{2}$ The 12 phyla are Firmicutes, Fusobacteria, Proteobacteria, Actinobacteria, Bacteroidetes, Chlamydiae, Chloroflexi, Spirochaetes, SR1, Synergistetes, Saccharibacteria (TM7) and Gracilibacteria (GNo2). ${ }^{3}$ At the genus level, there is a conserved oral microbial community in healthy mouths. Diversity in the microbiome is individual specific and site specific, despite the similarities. The tongue has numerous papillae with few anaerobic sites and hence harbours a diverse micro flora which also includes anaerobes. The areas with low microbial diversity are the buccal and palatal mucosae. ${ }^{4}$ The principal bacterial genera found in the healthy oral cavity are as follows. ${ }^{5}$

\section{Gram positive:}

1. Cocci: Abiotrophia, Peptostreptococcus, Streptococcus, Stomatococcus

2. Rods: Actinomyces, Bifidobacterium, Corynebacterium, Eubacterium, Lactobacillus, Propionibacterium, Pseudoramibacter, Rothia.

\section{Gram negative:}

1. Cocci: Moraxella, Neisseria, Veillonella

2. Rods: Campylobacter, Capnocytophaga, Desulfobacter, Desulfovibrio, Eikenella, Fusobacterium, Hemophilus, Leptotrichia, Prevotella, Selemonas, Simonsiella, Treponema, Wolinella. ${ }^{5}$

Centuries ago, clove, neem, salt and mustard oil were being used under homemade herbal aids that came to rescue by the elders in each family which are now being used globally and are well accepted when the leading pharmacy companies who have chosen the same in the toothpastes for their added benefits. Brushing teeth twice does not put an end to the dental hygiene regime but taking care of the gums alveolar bone and the tongue is equally valuable.

Oral rinsing after consuming meals is advised for the omission of the oral bacteria and deposition of plaque which adheres to the tooth surfaces after meals. Interdental brushes, floss, mouth sprays, dispensable paper-thin sheets, have been introduced to combat the bad breath. Today eco - friendly toothbrushes made of bamboo are available to avoid the plastic

(C) Taruna Malhotra. This is an open access article distributed under the terms of the Creative Commons Attribution License CC-BY-NC 4.o, which permits unrestricted use, distribution and reproduction in any medium, provided the use is not commercial and the original author and source are cited. 
handles, BPA- free bristles generally made of corn fibre or nylon fibres, environmentally sustainable with the ability to remove the bristles and place new ones. The usage of age old techniques which were once considered old- fashioned are trending now and a spurt can be seen in using and promoting the environment friendly products as nature has a lot to offer and contribute which can be utilised for the oral care and maintenance of oral health.

Periodontitis is the $6^{\text {th }}$ Complication of diabetes, the plaque deposits further increase with the glycemic values, If the HbiAc values are in good control it further enhances the oral hygiene. ${ }^{7}$

Cardio-vascular diseases are being affected by the $P$. gingivalis when the plaque deposits reach the blood stream and they are known to cause clots which lead to stroke, bacterial pneumonia, cardio-vascular diseases. ${ }^{4}$

In auto-immune diseases like sjgoren syndrome, bechet disease, SLE, candida albicans plays its role as the xerostomia conditions is a perfect environment which increases the risk of oral bacterial growth ${ }^{6}$, making the patients of auto immune diseases at a markedly higher susceptibility of bone, perio, endo perio lesions. Corticosteroids further damage the bone conditions and alveolar bone.

Whereas, the oral findings in chronic kidney disease implications it majorly depends on the glomerular filtration rate, generally observed lower renal rate increases the compromised oral conditions, The Kidney patients are often observed with apthous ulcers and halitosis and abnormal pigmentations are commonly seen. ${ }^{8}$

Research has proven the association of Parkinson's and Alzheimer's with teeth.

Adapting to the Preventive measures to abstain from an unhealthy oral microbial flora are that you must be regular with the dentists check-up like a 6 monthly visit to your family dentist is advisable and inculcate these habits in your prodigy, for a routine check-up keeps the problems at bay. Healthy lifestyle is a second major contributing factor which enhances the immune system the bone health and the oral hygiene, when the plate consists of a balanced diet compromising of protein, carbohydrates, minerals, probiotic and most importantly fibre.
From time and again emphasis of vitamin $C$ have gained momentum and acceptance but one misses out the benefits from Blueberries and Cranberries which are highly effective in protecting the teeth against a strand of bacteria responsible for accelerating tooth decay .

Oral cavity is the connecting bridge with the other organs of our body and henceforth one cannot neglect or keep it unhealthy. It's for your personal interest and awareness to maintain the parameters in accordance with oral hygiene to be disease free.

So, the question arises can you afford to continue lifelong medications due to systemic ailments caused by poor oral hygiene and prognosis or afford a 6 monthly consultation with a dentist.

Healthy Living is a priority and cannot be taken for granted as the repercussions might turn fatal.

\section{REFERENCES}

1. Jin LJ, Lamster IB, Greenspan JS, Pitts NB, Scully C, Warnakalusuriya S. Global burden of Oral Diseases: emerging concepts management and inter play with systemic health. Oral Diseases 2016;22(7):609-19.

2. Zhao H, Chu M, Huang Z, Yang X, Ran S, Hu B, et al. Variations in oral microbiota associated with oral cancer. Scientific Reports 2017;7:11773

3. World Health Organisation Cardiovascular (CVDS) Fact sheet updated May 2017.http://www.who.int/mediacentre/factsheets/fs3 17/en/ [Last accessed on March 28 ${ }^{\text {th }}$, 2019]

4. Joshipura KJ, RimmEB. Douglass CW, Trichopoulos, D, Ascherio A, Wiket WC. Poor Oral Health and Coronary Heart disease. J Dent Res. 1996; 75(9);1631-6.

5. Deo PN, Deshmukh R. Pathophysiology of keratinization. J Oral Maxillofac Pathol 2018;22:86-91 6. Julkunen A, Heikkinen AM, Söder B, Söder PÖ, Toppila-Salmi S, Meurman JH. Auto- Immune Diseases and Oral health; 30 Year -follow up of a Swedish cohort. Dent J (Basel). 2017 Dec 22;6(1):E1

7. Kane SF. The effects of oral health on systemic health. Gen Dent. 2017;65(6):30-4.

8. Oyetola EO, Owotade FJ, Agbelusi G, Fatusi OA, Sanusi AA. Oral findings in chronic kidney disease: implications for management in developing countries. BMC Oral Health 2015;15:24. 
Cite this article as:

Malhotra T. Population and Oral Hygiene (World Population Day Editorial

Comment). Int Healthc Res J. 2019;3(3):96-98.

https://doi.org/10.26440/IHRJ/0303.06245

Author Details \& Corresponding Address:

Dr. Taruna Malhotra

B.D.S, M.Sc. Forensic Odontology

Forensic Editor, IHRJ

tarunamalhotra7@gmail.com 